\title{
Exploring the meaning of trauma in the South African Police Service: A systems psychodynamic perspective
}

\author{
Authors: \\ Marna Young ${ }^{1}$ \\ Pieter Koortzen² \\ Rudolf M. Oosthuizen ${ }^{3}$ \\ Affiliations: \\ ${ }^{1}$ Clinical Psychologist, Private \\ Practice, Pretoria, \\ South Africa \\ ${ }^{2}$ Department of Industrial \\ Psychology and People \\ Management, University of \\ Johannesburg, South Africa \\ ${ }^{3}$ Department of Industrial \\ and Organisational \\ Psychology, University of \\ South Africa, South Africa \\ Correspondence to: \\ Pieter Koortzen \\ Email: \\ pieter@savilleconsulting. \\ co.za \\ Postal address: \\ Suite \#101, Private Bag \\ X9976, Sandton 2146, \\ South Africa \\ Dates: \\ Received: 05 July 2011 \\ Accepted: 30 Apr. 2012 \\ Published: 25 June 2012 \\ How to cite this article: \\ Young, M., Koortzen, P., \& \\ Oosthuizen, R.M. (2012). \\ Exploring the meaning of \\ trauma in the South African \\ Police Service: A systems \\ psychodynamic perspective. \\ SA Journal of Industrial \\ Psychology/SA Tydskrif vir \\ Bedryfsielkunde, 38(2), Art. \\ \#1004, 11 pages. http:// \\ dx.doi.org/10.4102/sajip. \\ v38i2.1004
}

C 2012. The Authors.

Licensee: AOSIS

OpenJournals. This work

is licensed under the

Creative Commons

Attribution License.
Orientation: This study explores individual stories of trauma and their dissonance with the official, dominant discourse on trauma in the South African Police Service (SAPS) from a systems psychodynamic perspective.

Research purpose: The purpose of the research was, firstly, to explore how trauma experienced by South African Police Service members is constructed or 'talked about' and made sense of. Questions and issues that are considered relevant to the primary purpose are: which aspects of the working environment do members consider to be the most stressful, traumatic and difficult to cope with, and what is the effect of the change and transition processes on members' working experiences?

Motivation for the study: The authors set out to explore the role of systems psychodynamics in the experience of trauma and stress in the SAPS.

Research design, approach and method: Through this qualitative, explorative, social phenomenological study, contributing circumstances and processes are included as additional discourses in an attempt to deepen understanding. The epistemology viewpoint of the study is found in the social constructionism and the data comprise 15 essays by members of the SAPS, all of which have been analysed from the perspective of systems psychodynamics.

Main findings: Although the effect of trauma on police officers can never be negated, the way in which they deal with trauma seems to be different from what was initially believed. Further, their experience of stress is not solely the result of traumatic experiences but rather the result of traumatic experiences and systems psychodynamics operating within their organisation which includes both organisational stressors or dynamics and transformation dynamics.

Practical/managerial implications: The history of psychological trauma indicates that constructions of traumatic stress are strongly related to cultural, social and political circumstances. Current psychoanalytic thinking emphasises the meaning of the real occurrence, which causes trauma by changing the person's experience of the self in relation to self-objects. Practical implications are the loss of the supportive subculture of the police, the loss of masculinity, as well as the loss of the power to be competent and meaningful. Furthermore, feelings of being overwhelmed, powerless and helpless generate anxiety and may have a significant impact on officers' self-esteem and impede their feelings of omnipotence and invulnerability, which are necessary to cope in the policing environment.

Contribution/value-add: The current study found various traumatic and systemspsychodynamic factors and processes to be anxiety-provoking as a result of exposure to trauma. Without a supportive social group the anxiety becomes uncontained and unmanageable.

\section{Introduction}

\section{Key focus of the study}

As in other qualitative research studies, the researchers would like to start at the non-traditional beginning, namely their personal involvement in the research topic. The first researcher explained that she was trained as a clinical psychologist and that she has been employed in the Psychological Services Unit (previously known as Behavioural Sciences) of the South African Police Service (SAPS) for 12 years, of which the last eight years have been spent mainly in doing psychotherapy with police members. In addition to the main focus on psychotherapy, her duties have included crisis intervention, suicide prevention, trauma counselling, trauma debriefing and hostage negotiation. In recent years she has become aware of a dissonance between the official discourse on trauma in the SAPS and the individual stories which members disclose in psychotherapy. She has become interested in exploring this further and it has emerged as a topic for research. 
The second researcher used to be employed in the SAPS as a psychologist and has been working with traumatised individuals for the past 18 years. As part of his role in the SAPS the researcher helped to design the first trauma debriefing training programme for psychologists and peer debriefers in the police. This afforded the researcher the opportunity to explore the meaning of trauma from a different stance and an opportunity to contribute to the understanding of trauma from a systems psychodynamic perspective.

The third researcher has conducted numerous research projects of a similar nature, evaluating the impact of stress and trauma amongst groups of emergency workers, and has a keen interest in understanding the systems psychodynamics in the two different systems. Our paradigm as psychologists is mainly grounded in psychoanalysis and specifically the systems psychodynamic perspective, which has influenced our interpretation and analysis of content.

Our thinking on the subject of trauma in the SAPS has led us to the perspectives outlined below. What seems to be emerging is that trauma (referring to the experience of a traumatic event) is blamed for most of the SAPS's ills. When commenting on issues such as the high suicide rate, the number of medical boardings, police brutality and corruption, the SAPS's spokesperson generally refers to the amount of trauma that police officials experience. Traumatic incidents involving police members are often reported in the media, particularly from 2000 to date. For example, the heading of an article in Beeld in 2000: 'Trauma in die polisie kan geweld kweek' [Trauma in the police may foster violence] (Anonymous, 2000). Another article (Otto, 2002) with the heading 'When the price is too high ... Cops struggle to cope with stress on the job', implies that job stress and trauma are synonymous. Last-mentioned article further suggests that the experience of traumatic events is the main reason for the emotional difficulties experienced by SAPS members. The implication of these and other similar constructions is that other factors, which might contribute to or aggravate the experience of trauma, are ignored in the official SAPS discourse.

In an article, entitled 'Polisie kort berading' [Police in need of counselling] (Sapa, 2009), the argument was made that police officers should be trained to identify and manage their own stressors and frustrations and not to take these out on the general public. This article therefore refers to both trauma and stress (or frustration), which can lead to further violence against members of the public. This does not mean that we negate the effect of trauma on police officers. Furthermore, this article does not deny or belittle the harrowing impact that traumatic incidents have on police members. Nor does it disregard the number or horror of the scenes members attend, or the frightening and anxiety-provoking situations they experience. The authors believe, however, that a broader exploration of contributing circumstances and processes might lead to additional discourses on members' experience of trauma. The research purpose can therefore be presented in the following manner.

\section{Research purpose}

The purpose of the research was firstly to explore how trauma experienced by SAPS members is constructed. Questions and issues that are considered relevant to the primary purpose are: which aspects of the working environment do members consider most stressful, traumatic and difficult to cope with, and what is the effect of the change and transition processes on members' working experiences? Secondly, the purpose was to explore the role of systems psychodynamics in the experience of trauma and stress in the SAPS.

\section{Background to the study}

The background to the study is presented by firstly explaining the context of the research and secondly, the concept of trauma. This should provide the reader with an understanding of the milieu in which the research was conducted and the researchers' specific definition of trauma.

\section{Stress and trauma in the South African Police Service}

According to Seedat, Van Niekerk, Jewkes, Suffla and Ratele (2009), violence and injuries are still the second leading cause of death and disability in South Africa. These authors also found that South Africa's injury death rate is nearly twice the global rate average. They also found that the high injury death rate is driven mainly by interpersonal and genderbased violence, followed by traffic injuries, self-inflicted injuries, and other unintentional injuries arising from fires, drowning and falls. As a result of this, traumatisation and suicide amongst SAPS officials has soared.

Policing in South Africa is a dangerous job; for example, 54 members lost their lives in the line of duty from July 2002 to July 2003. These figures increased significantly in 2006, with 51 police officers losing their lives in the first half of 2006. The latest available data indicate that the death rate is still significantly higher than the global average, with 109 officers being killed on duty in 2008 and 2009. According to Botha (2002), police officers are confronted with a myriad of anthropological-existential problems:

The country is still in a process of transformation, the South African Police Service is confronted with an unacceptably high crime rate and the individual in the organisation has to cope with extremely serious psychological problems. (p. 48)

This situation may even lead to suicide ideation by some members (Pienaar, Rothmann \& Van der Vijver, 2007).

The identity of the SAPS is characterised by an intense, mostly forced transformation process, which has numerous implications, such as a decay of the in-group identity (Van der Westhuizen, 2001), and feelings of uncertainty and insecurity (Nel \& Steyn, 1997). Apart from the dangers that they deal with on a daily basis, police officers also face a number of other challenges. In order to explain our thesis that a broader exploration of contributing circumstances and processes, which include systems psychodynamics, might lead to additional discourses on members' experience of trauma, the following research is presented. 
Mostert and Rothmann (2006) assess whether background variables, job stress and personality traits can predict the work-related well-being (burnout and work engagement) of police members. The results show that age, gender and race explained a small percentage of the variance in exhaustion, cynicism, and vigour and/or dedication. Stress resulting from job demands and a lack of resources predict exhaustion and cynicism. Emotional stability and conscientiousness inversely predict exhaustion and cynicism, whilst emotional stability, conscientiousness and extraversion predict vigour and dedication. Stress because of job demands predicts only a small percentage of the variance in vigour and dedication. This research supports our belief that more factors than simply trauma may determine the ability of police officers to cope.

We are in agreement with the finding by Kassen and DiLalla (2008) that police work has been recognised as high risk for exposure to traumatic events and the ensuing potential to develop posttraumatic stress disorder. However, not all officers exposed to traumatic events develop symptoms of traumatic stress, although they may continue to express subjective stress. These authors identify ego defence styles and the dispositional construct of sense of coherence as variables that can possibly affect an officer's stress response and their results suggest that a model that includes maladaptive defences can prove more informative when the primary objective is the assessment of traumatic stress responses. This research provides an alternative perspective on traditional trauma responses.

This change in the identity and culture of the organisation appears to be more difficult than expected and the differences between members are even evident in the new recruits. Steyn (2007) compares the presence of police culture thematic attitudes amongst male and female newcomers upon their arrival for basic training. The results indicate that the organisational culture is in flux and that police officers will also have to cope with the political and societal nuances and systems dynamics of the time.

Ketel (2008) focuses her research on the managerial capacity of the officers at station level within the SAPS. The research indicates great variations in the levels of managerial capacity of managers and identifies the need for a management development intervention. According to Marks (2008), the transformational process is still problematic and six years after the transformation process began, it is still plagued by deep racial and gender divisions.

These divisions and the problems involved in developing an integrated organisation are also explored by Bucaille (2006), who explains that police officers who served under apartheid now admit that non-racial democracy is a more legitimate system. These former police officers also reject any personal responsibility for their work during the apartheid era. This distancing strategy makes expressing and developing a collective identity problematic, however. The authors also acknowledge that these officers are not slow to show pride in their work. In order to preserve their self-esteem they attempt to reconcile contradictory positions, pleading not guilty to the charges of supporting apartheid whilst claiming personal merit for having participated in the war undertaken by the regime. Their discourse is therefore profoundly ambivalent. The systems dynamics of the past can therefore not be ignored when exploring the traumatic and stressful experiences of police officers.

\section{The concept of trauma}

For the purposes of this discussion the following two psychodynamic definitions of trauma are deemed important. Garland (1998, p.11) defines trauma as 'an event that overwhelms existing defences against anxiety in a form which also provides confirmation of those deepest universal anxieties'. Lindemann (1944) defines psychological trauma as the sudden, uncontrollable disruption of 'affiliative bonds', a term that alludes to the importance of social support. Disruption or loss of social support is intimately associated with the inability to overcome the effects of psychological trauma (Janoff-Bulman, 1985; Pynoos \& Eth, 1985). According to Krystal (1978), it is not the intensity of the experience but the meaning for the individual that 'posed the challenge and generated the affective response', which caused the ultimate post-traumatic adaptation. Against this description of the background to the research and these definitions of trauma, a more comprehensive literature review can be presented.

\section{Literature review}

Given that the SAPS is the institution studied in relation to trauma and systems psychodynamics, this section provides an overview of the transformation in the SAPS, the psychodynamic theory of trauma and the basic assumptions of the systems psychodynamic approach.

\section{Transformation processes in the South African Police Service}

The SAPS went through a number of strategic changes since the historic change in government in 1994 (SAPS, 1994; SAPS, 1995; White Paper on Reconstruction and Development, 1994). Before 1994 the top structure comprised mainly White males and many of the changes were focused on bringing about race and gender equality, especially in managerial positions:

The police command did much to put black faces in the front window, but in the absence of a policy of lateral recruitment from the outside, had little talent with which to work. (Steinberg, 2001, p. 9)

The transformation process of the police is primarily characterised by a movement towards democratic control over the service. Values that have been accepted include accountability, transparency, community consultation and involvement, as well as an emphasis on the quality of service delivery (Van der Westhuizen, 2001).

Although South Africa is searching for its own model of policing, taking into account the unique aspects of South 
African society, for some time this country has implemented an approach which was in line with the British liberal model of policing (Brewer, 1994). This is a model that emphasises decentralisation, an absence of militarism and arms, and a police membership that fairly represents the social composition of society as a whole. The problem, as noted by Brewer (1994), is that the liberal model of policing was implemented in South Africa at a time when the model was already coming in for a certain amount of criticism in academic police science literature. In spite of resistance from POPCRU via their national spokesperson Norman Mampane (2010) against the reimplementation of the military system, the government decided to do so in 2010.

\section{Impact of change and transformation on the police subculture}

The SAPS had a subculture in which there were rigid boundaries between 'us' and 'them'. As Ainsworth (1995) says: 'For any group whose authority, status and role is challenged frequently, solidarity with other in-group members becomes increasingly important' (p. 14). This police culture became enshrined in official organisational structures, policies and procedures, many of which contributed to social isolation. Although this social isolation had a protective function and provided the emotional and professional support members needed as a buffer against stress, it also contributed to an us or them mentality and to a separation between the police and the community (Nel, 1994). This divide often further entrenched the racial segregation between White and Black. According to Botha (2002), the perception of continuous danger played an important role in the police's alienation from the community. The constant scrutiny of the police by the public and media further contributed to the closing of ranks by the police service and increased suspicion of outsiders. The in-group identity of police officers is noticeable in the methods used to deal with the stress and trauma associated with the job. Trauma is mostly dealt with within the inner circle and wives or significant others are often excluded (Van der Westhuizen, 2001). This often leads to distancing and problems in intimate relationships. The methods mostly used to deal with stress and trauma include the use (and abuse) of alcohol, denial, joking and socialising - often exclusively with fellow officers.

\section{Theoretical concepts linked to a psychoanalytic theory of trauma}

According to psychodynamic theory, traumatised individuals are faced with the task of integrating the traumatic event into their understanding of the meaning of life, self-concept and world image. The emotional reactions of traumatised individuals are viewed as the result of discrepancies between internal and external information (Horowitz, 1986; Horowitz \& Kaltreider, 1980; Schwartz, 1990; Wisdom, 1989). The following section attempts to present the theoretical concepts of a psychoanalytic perspective of trauma.

Traumatic memory versus ordinary memory: Ordinary memories fade and merge into the past. Years after its creation trauma can, however, remain unassimilated, a selfrenewing presence, perpetually reliving the moment of its origin (Herman, 1992; Van der Kolk, McFarlane \& Weisaeth, 1996). Immediately after a traumatic event, almost everybody suffers from intrusive thoughts about what has happened (McFarlane, 1992). Either the event is integrated into memory and stored as an unfortunate event belonging to the past, or the sensations and emotions belonging to the event start leading a life of their own. One of the serious complications that interfere with healing is that one particular event can activate other, long-forgotten memories of previous traumas, and create a 'domino effect'. These traumas can play out in anxiety and dreams.

Trauma, memory and a sense of self: Reiker and Carmen (1986) point out that after the trauma the victim's view of self and the world can never be the same again; it must be reconstructed to incorporate the abuse experience. Age and previous life experiences have a profound effect on a person's interpretation of the meaning of the trauma and assuming responsibility for the trauma allows feelings of helplessness and vulnerability to be replaced with an illusion of potential control. Shame is the emotion related to having let oneself down (Cole \& Putnam, 1992; Pearlman \& Saakvitne, 1995).

Fear, pain and defences: Fear, along with the element of surprise, is an assault equivalent or analogous to physical violence. Some victims develop strategies and routines that allow them to avoid harmful stimuli (phobias); other victims simply give up (learned helplessness); and thirdly, victims of traumatic experiences may seek out circumstances that replicate their traumatogenic events. According to Young (1995), pain (or 'withdrawal') may build up to the point where individuals are induced to self-dose with endorphin by re-exposing themselves to traumatogenic-like situations.

Avoidance, numbing and dissociation as defence mechanisms: The human response to sudden and overwhelming events is to respond to stress in an all-ornothing way: either unmodulated anxiety, often accompanied by motoric discharge that includes acts of aggression against the self or others, or else social and emotional withdrawal (Burgess \& Holmstrom, 1974; Figley, 1978; Green, Wilson \& Lindy, 1985; Horowitz, 1986; Krystal, 1978). Dissociation is a normal part of the psyche's defences against the potentially damaging impact of trauma. Contemporary psychoanalysis recognises that where the inner world is filled with violent aggression, primitive defences are present too. The energy for dissociation originates from this aggression.

The role of meaning in the experience of trauma: The personal meaning of a traumatic experience evolves over time, and often includes feelings of irretrievable loss, anger, betrayal and helplessness. The critical element that makes an event traumatic is the subjective assessment by victims of how threatened and helpless they feel (Van der Kolk et al., 1996). A crucial element of an experience that becomes a trauma is the aspect of loss, be it loss of life, possessions, integrity or beliefs. Usually, suffering does not bring an increased sense of love and meaning; it more often results in loneliness and disintegration of belief (McFarlane, 1992). The inability 
to take action in many traumatic instances emphasises the helplessness, which triggers issues of vulnerability and dependency.

Meaning and perceived support: The personal meaning of traumatic experiences for individuals is influenced by the social context in which they occur. Victims and the significant people in their surroundings may have different and fluctuating assessments of both the reality of what has happened and of the extent of the victim's suffering. This, in turn, may lead to the allocation of blame and responsibility, and this, rather than the trauma itself, often becomes the central issue (McFarlane, 1992).

\section{Basic assumptions of the systems psychodynamic approach}

Systems psychodynamics is an interdisciplinary field that integrates three disciplines: the practice of psychoanalysis, the theories and methods of group relations, and open systems perspectives. Systems psychodynamics is 'a term used to refer to the collective psychological behaviour' (Neumann, 1999, p. 57) within and between groups and organisations.

Bion (1961) hypothesises that groups have two modes of operation. He calls one mode the productive sophisticated group, more commonly called a work group. A work group focuses intently on the group's task and maintains close contact with reality. Bion (1961) calls the other mode of group operation basic assumption. Its primary task is to ease the group's anxieties and avoid the pain or emotions that further work might bring. The group assumes that this leader, whether formally or informally selected, has clairvoyance of thought and supernatural powers and that the rest of the group is powerless and dependent. When the leader fails to meet the group's unrealistic expectations, as he or she inevitably does, the group quickly becomes frustrated and disappointedly selects another member for the daunting task (Bion, 1961).

The basic assumption mode of pairing is evident in a group when the groupinvests irrational hopefulness for the future in two of the group members. Regardless of gender, the group assumes that these two individuals have paired either for a 'sexual' experience, which would give rise to the birth of a new group, a religious experience, which would provide a messiah, or a reparative experience, which would produce world peace.

When a group operates in the basic assumption mode of fight-flight, Bion writes that the group seems to know only two techniques of self-preservation, fight or flight and the kind of leadership that is recognised as appropriate is the leadership of the man who mobilises the group to attack somebody, or alternatively to lead it in flight (Bion 1961). The following two additional assumptions were later added to Bion's (1961) original assumptions.

One-ness: According to Turquet (in Lawrence, Bain \& Gould, 1996) the assumption is that team members seek to join into a powerful union with an omnipotent force, surrendering the self for passive participation, thus experiencing existence, well-being and wholeness.

Me-ness: As the opposite of one-ness, this assumption refers to the risk of living in our contemporary, turbulent society. The individual is pushed more and more into his or her inner reality in order to exclude and deny the perceived disturbing reality of the outer environment. The inner world becomes the comfortable place and the outer world the one to be avoided. The team works on the tacit, unconscious assumption that the group is to be a nongroup. Apart from these basic assumptions, Koortzen and Cilliers (2002) refer to other constructs that form part of the systems psychodynamic approach. These include projection, projective identification, resistance to change, boundaries, taking up a role, representation, authorisation, relationship and relatedness.

\section{Research design Research approach}

The research approach comprises a qualitative, explorative, social phenomenological study (Mouton, 1996). The epistemological orientation of this research falls within social constructionism, based on the principle that all knowledge is socially constructed (Hoffman, 1993). The human world of experience is worthy of examination and this study will contribute to new ways of understanding the way trauma is experienced in the SAPS.

\section{Research strategy}

In order to contextualise participants' narratives, each completed a brief questionnaire eliciting biographic information and a brief description of job functions. The questionnaire was available in English and Afrikaans. In the current study it was decided to utilise the written language in the form of essays, rather than interviews, since this is a novel way of collecting data in the context of the SAPS. According to Penn and Frankfurt (1994), adding writing to conversations in research hastens the discovery of new voices and promotes the creation of new narratives.

Each participant was presented with the following request: 'You have worked in the Special Task Force, Highway Patrol or Crime Combatting Unit for the last couple of years. In all jobs there are highs and lows, events that are good and those that may cause a lot of stress and trauma. Write an essay in which you explain what you like about your job and that which you do not like about your job. You may comment on changes you experience in your working environment (if any) and how that has impacted on you. Explain what you think causes the difficulties that you might experience.'

\section{Research method}

In the following section the research method is described in terms of the research setting, the way entry was obtained 
to the research setting and how the researcher roles were established.

\section{Research setting}

The participants were recruited from within the South African Police Service. Three units were selected. The selection of these units was influenced by practical and logistical factors. The selected units are the Special Task Force (STF), the Highway Patrol Unit (HPU) and the Crime Combatting Unit (CCU). The STF is a highly specialised operational unit with the most stringent selection and training procedures (nine months) in the SAPS. The HPU operates on a provincial level, and members are stationed at Flying Squad centres in different areas. Highway Patrol forms part of the Police Emergency Services structure, together with, for example, the Radio Control Centres and the Water Wing. The CCU's main function is to combat crime.

\section{Entrée and establishing researcher roles}

The study called for 'healthy' participants as opposed to officers who label themselves or are labelled by others as 'traumatised'. This eliminated the option of recruiting members receiving therapy or those in the process of being medically boarded. The commanding officer of each unit was informed about the study (as police protocol requires), and was requested to identify five members to participate in the research. The first commander gave his consent for members of his unit to participate in the study, but he did not nominate members and referred the researchers to his operational officer, who nominated five members. At the second unit an operational officer nominated five members. The third unit's commanding officer also referred the researchers to an operational officer for the nomination of members. All of the above people were contacted telephonically. None of the commanders volunteered to participate in the study themselves.

\section{Sampling}

For the current study, five participants were recruited from each unit, making 15 in total. Practical considerations mainly informed the sample size. All 15 participants were male. The age of participants ranged from 27 to 47 years of age, with an average age of 34.1 years. Both White and Black police officers participated in the study. One held the rank of Senior Superintendent, one that of Superintendent, two that of Captain, eight that of Inspector and three that of Sergeant. Nine were Afrikaans speaking, three were English speaking and three spoke an African language. Thirteen participants were married and two were single, with only one participant in a second marriage. Fourteen participants had children. Regarding level of schooling, all the participants had passed Grade 12 and eight held a National Diploma in Police Administration.

\section{Recording of the data}

Interaction with participants was limited to one or sometimes two interviews. This renders the level of disclosure in the essays so much more significant. The participants mainly shared experiences with insight, openness and honesty. Some participants even mentioned the names of commanding officers, which might land them in trouble if the facts became known. This was done partly to lend more credibility to their stories. They put a lot of time and trouble into narrating their stories. The participants mentioned that this was the first opportunity any of them had ever had to tell their stories. They mostly felt ambivalent at the end of their stories, stating that it was good to air their stories and get it 'out of their systems', but they questioned whether this would change anything.

\section{Data analysis}

The data was analysed using a thematic analysis informed by Marshall and Rossman's (1995) non-linear model for analysing qualitative data. Organising the data involved the close and repeated reading of the essays, which allowed the researchers to gain a holistic grasp of the data. Notes were generated regarding ideas related to the text. Generating categories, themes and patterns involves the identification of salient themes, recurring ideas and patterns that link people and settings together. This required us to question the data and reflect on the conceptual framework upon which the present study was formulated. Generating categories included selecting, simplifying, abstracting and transforming the data. Coding categories were developed to assist with the procedure. In this way, meaning could be ascribed to the descriptive information compiled during the study.

\section{Strategies employed to ensure quality data}

After selecting the final themes and mapping their possible inter-relationships, quotes were selected. Quotes were selected which were representative of the sample and which could best illustrate a particular issue. The participants were assigned letters of the alphabet in order to disguise and protect their identities. The actual essays were not included as the identities of participants could be readily apparent to those acquainted with them. The quotations were translated into English for presentation purposes. The translation was done by an independent source and was counterchecked to enhance textual accuracy. In reporting the data, the lifeworld of members of the SAPS was described in relation to traumatic experiences and the subjective meanings they attached to their experiences. The experiences and meanings of their latent or meta-communications were interpreted in the light of broader theoretical contexts, namely the systems psychodynamic approach.

Trustworthiness: Qualitative research transcends rigid formality and objectivity by introducing transparency without comprising the research process, thereby enhancing trustworthiness (Bruinsma \& Zwanenberg, 1992). Qualitative methods take the researchers' communication with the field and its members as an explicit part of knowledge production instead of excluding it as far as possible as an intervening variable (Uwe, 1998). Subjective elements related to the researchers and the subjects are part of the research process 
and the reflections on the research process are included as such. This involves the researcher's active engagement with participants and acknowledges that understanding is constructed and that multiple realities exist. Participants' accounts are valued and emergent issues within the accounts are attended to. The developing theory is thus firmly and richly grounded in personal experiences rather than being a reflection of the researcher's framework. In this way insight is gained into the meanings people attach to their experiences (Jacobs, 2000).

Authenticity: The researchers also attended to authenticity in terms of the wider political impact of the research. Participants from different race and age categories were included in an attempt to ensure fairness by obtaining as many different opinions as possible. Ontological and educational authenticity was achieved by assisting participants to arrive at a better understanding of their social situation and develop an appreciation of the perspectives of others with regard to trauma in the SAPS. This was done by sharing different perspectives during the formal feedback sessions with the participants and answering their questions in an open and honest way during these feedback sessions.

\section{Findings}

Extracts from the findings are discussed in terms of the two main themes that emerged from the data. These themes are traumatic incidents and systems psychodynamics, consisting of organisational and/or systems stressors and transformation. It is important to note that selected themes cited in the participants' essays are discussed in this section.

\section{Theme 1: Traumatic incidents}

Exposure to traumatic situations and scenes is an inevitable part of the job of policing. Most police officers report relatively low levels of death anxiety despite their dangerous profession:

'Trauma in my work is almost like a daily routine, we experience it almost everyday.' (Particpant K, member of South African Police Service)

'The work of the SAPS STF is very dangerous and every time a member gets sent on a mission, his life is on the line.' (Participant $S$, member of South African Police Service)

Although most participants experience the death of a colleague as traumatic, they do not consider it overwhelming:

\begin{abstract}
'Another traumatic time for me, was the death of two of my colleagues in a state vehicle accident. One of them was our commander at the time and a very good friend of mine. This incident obviously affected the whole unit, but I don't think we were ever properly debriefed. Everyone had to deal with this in his or her own way. I feel I dealt with it, but these incidents will always stay with me.' (Participant A, member of South African Police Service)
\end{abstract}

The unit is spoken of as a living entity. The whole unit was touched by the loss of two of its members and although they received no psychological intervention (which may be interpreted as support from management), the participant feels that he dealt with this loss in his own way. These incidents were integrated into his ego and became part of his history, and he considers this to be a normal way of coping with trauma.

A sense of meaning was attached to the death of the police officer who was killed in pursuit of a 'cop killer'; he died for a reason, whereas the death of the officer who was killed whilst cycling was regarded as senseless and devoid of meaning. The employment of religious beliefs in seeking to attach meaning to traumatic experiences is clearly illustrated in the next insert:

'Then there was $X$ whose parachute did not open during a training jump at $\mathrm{Y}$ with the SANDF. He was with me in the plane and exited behind me. I was the first person to find his body and had to deal with the sight and smell I saw. I did this by setting the example as I was the senior member from the police on the training intervention. I proceeded to handle the scene as professionally as possible without emotion, getting everybody involved. Once again my defence was to block out any emotional thoughts and replace them with the spiritual reality that his body is destroyed but he lives on elsewhere.' (Participant N, Member of the South African Police Service)

Anger, aggression and irritability are commonly associated with traumatisation. In the following excerpt, a participant describes his feelings of anger after arresting robbers who shot at a group of which he was part. The anger is directed at the robbers as well as at colleagues who were not at the scene but criticised what had happened there. Again, there is the notion that anyone who was not part of the specific incident, whether or not they are other police officers, cannot understand what it was like:

'Although, later one regrets it that the robbers are not dead, because they shot to kill us. It was an unfair battle. Some people criticise one's actions afterwards and say that they would have handled it better ... Then I think to myself: "do not comment if you were not part of that which happened when it happened."' (Participant C, member of the South African Police Service)

The sense of having been abandoned by the department was a common complaint amongst injured policemen. This is often perceived as a lack of support:

'In 2001 I had a serious motor vehicle accident ... During my stay in hospital my unit commander visited me once. There were no visits from colleagues.' (Participant L, member of South African Police Service)

'In none of the above cases did my unit commander refer me to helping professions for counselling or for debriefing after a traumatic event.' (Participant L, member of South African Police Service)

\section{Theme 2: Systems psychodynamics}

This theme consists of organisational and/or systems stressors and transformation.

\section{Organisational and/or systems stressors}

Police stress is defined as a perceived imbalance between what is required of officers and what they are capable of giving, under conditions where failure may have dire consequences 
(McGarth, 1992). Failure to respond to demands in policing is often associated with harm or death. All participants in the current study concurred that organisational stressors have an extremely negative impact on their functioning as police officers, their well-being and their lives as a whole.

Training: The training of police officers has dual relevance to this research. Firstly, there is the level of competency that officers themselves experience, and secondly, their perception of their colleagues' level of competency. Both of these impacted on the officers' sense of safety and adequacy, which in turn is linked to their sense of self. This is one of the areas where inadequacy may have serious consequences; untrained officers are a liability to themselves, their colleagues and the public alike. Adequate training makes them feel prepared and equipped for the job at hand:

'Even though the training was physically very demanding, and you worked under lots of pressure, I believe that I am better equipped, and better trained to do every job that is required from me.' (Particpant L, member of South African Police Service)

Recognition: Feeling supported and recognised alleviates feelings of vulnerability and acts as a 'trauma membrane'. In addition, the psychodynamic perspective on policing considers promotion, commendations and higher salaries as emotionally important since they symbolise the department's approval or recognition of officers by rewarding them for being 'special'. Participants cite the low salary that they earn as proof that they are not valued for the work they do and the risks they take:

'We are a specialising unit and not treated as that. The allowance that was meant for us is taken away. Five years has past since we were promised to receive an allowance and yet nothing has happened thus far. This makes members to leave our unit and join the private sector where the money is good.' (Participant F, member of South African Police Service)

Perceptions about commanders and management of the SAPS: Commanders and management are seen as the personification of the 'organisation' and often as the people in power who make the decisions. According to the psychodynamic viewpoint, a policeman's unconscious emotional experience is that he is the child and the department is either a powerful, nurturing parent or a bungling, punishing one:

'We heard later that $X$ is leaving on medical grounds. The founder and "godfather" of the unit doesn't want to be part of this circus any longer.' (Participant M, member of South African Police Service)

The impact of organisational stressors on relationships: Relationships within the police service can be broadly grouped into three clusters, namely relationships with colleagues, relationships with friends outside the police service and family relationships. Relationships with co-workers are considered important and have a highly supportive function. The literature indicates that police officers rarely socialise with non-police officers, which leaves family relations as the only other area of social support:

'During this period, I relied heavily on my wife for support. Whenever something bothers me, I usually talks about it to my wife. Even though I feel it's good for me to talk about it, I think it might have a negative effect on her.' (ParticipantA, member of South African Police Service)

Working environment: Police officers who perceive their working environment as uncontrollable (external locus of control) are more likely to be utilising emotion-focused coping, which is associated with a poorer prognosis for their mental well-being. Alcohol abuse is often one of the means police officers use to cope with their working environment:

'The trauma caused by all these incidents and situations have led to excessive drinking. At one stage I was drinking daily and getting drunk most days. I come to realise that I must set an example for my kids and that the situation I was in was not anybody's fault. I think the realisation that the way things are going is a normal reaction of any person or persons that have been oppressed, woke me up. I still have a few "toasts" but do not get drunk any more ... I spent time with my wife and children and I spent more time with my Maker. I try to go to church more often. I got involved with school activities ... I think that when I started to realise that there is life outside of my working hours, and that I am not responsible for everybody, I became less stressed and traumatised.' (Particpant E, member of South African Police Service)

This insert indicates ways in which defence mechanisms such as rationalisation may help to restore a sense of control over a situation, which encourages more adaptive ways of functioning. The shift away from the working environment to activities and people who are considered important contributed to this participant's coping. The conscious increase of distance from the working environment is perceived as an act of survival. The implied message is that the working environment is killing that part of him which is 'good' and 'decent'.

\section{Transformation}

SAPS officers face two major stresses: the inherent problems of an often dangerous, violent and underappreciated job, and the pressure of working in an organisation which is being fundamentally transformed.

Racial tension: It is a sensitive topic and probably the issue in the SAPS which is least acknowledged at an official level. For various reasons, including our colonial and apartheid history, racial issues in South Africa and the SAPS in particular are imbued with fear, guilt, anger and anxiety. In their relationship with one another, Black and White men have not only been divided by history and geography; they have related to one another in particular and hierarchical ways. Since the inception of the 'new' (anti-apartheid) South Africa and the revamped SAPS, racism, or the perceived unfair advantage of one racial group over another, is considered to be a serious organisational stressor by the White, male participants:

'Apparently racism does not exists in the new South Africa. "Ha-ha!" racism is alive and well and the only thing that's still advancing in the SAPS and its coming from both sides. Both my previous and present direct commanders are two of the biggest racists that I ever encountered in the SAPS. It causes tension 
between members when some ethnic groups are deliberately favoured above others. This is one of the main reasons of conflict between Black and White members at HP. It is wrong for someone in a managerial position to be guilty of such serious misconduct.' (Participant M, member of South African Police Service)

Representivity: As part of the transformation process in the SAPS, an objective is that the personnel compilation reflects the country's demographics with regard to race and gender. The Employment Equity Act 55 of 1998 aims to ensure that suitable people from designated groups are equally represented in all occupational levels and categories. This is experienced as discrimination and a lowering of standards by the White male participants:

'When it came to the selection of new HP members, the emphasis shifted from high standard to "representivity". A lot of members left the unit for other units in the SAPS or better jobs in the private sector. Unfortunately, members who were selected because of their race and not their expertise replaced these members. This obviously created a lot of distrust and conflict within the unit. I just didn't feel confident working with a member who didn't have the same level of training than we did. As time went by, the unit went into a downward spiral.' (Participant A, member of South African Police Service)

Unclear line of command and/or cumbersome organisational structure: Another change in the SAPS that is associated with the transformation of the organisation is an unclear line of command or a cumbersome organisational structure. Participants experience the command structure as cumbersome, clumsy and uncontained in a managerial sense:

'I don't really know how it happened but suddenly our unit commander had less of a say in our duties. Other officers at Area and Provincial level decided what we had to do.' (Participant C, member of South African Police Service)

The effect of the change: All participants experienced the recent changes in the organisation as negative. In contrast to the sense of meaning and purpose that was associated with the job of policing in the past, participants currently question the meaning of their function:

'We were being used more and more as a show-unit and not what we were trained for (combatting of serious crime). We were not allowed to respond to any complaints or crime in progress, even if we were in the immediate vicinity. This was very frustrating and demoralising for all of us. Crime was rife in $\mathrm{X}$, but we had to drive behind a bus ... or stand at stationary points on the highways. This instruction shocked me. How could anyone who says that he is serious about reducing crime in this country, issue an instruction like that? Was this man involved in crime himself and was he trying to get us out of the way? All these questions were going through my head as I was trying to make sense of this. We actually worked these insane duties for nine months. During this period I could hear crimes in progress being broadcast and the operator battling to find vehicles to respond to these complaints, but we were not allowed to respond. The crime rate escalated. Instead of putting our unit to the use it was intended for, new units were started with new vehicles. Do the SAPS have too much money or is it managed by a bunch of morons?' (Participant A, member of South African Police Service)

\section{Discussion}

The purpose of the research was, firstly, to explore how trauma experienced by South African Police Service members is constructed or 'talked about' and made sense of. Questions and issues that are considered relevant to the primary purpose are: which aspects of the working environment do members consider to be the most stressful, traumatic and difficult to cope with, and what is the effect of the change and transition processes on members' working experiences? Secondly, the authors set out to explore the role of systems psychodynamics in the experience of trauma and stress in the South African Police Service.

A number of hypotheses are presented. Firstly, a number of hypotheses on the meaning which police officers attach to their experience of trauma will be presented, where after a number of systems psychodynamic working hypotheses will be presented on the behaviour manifesting in the SAPS environment.

\section{Hypotheses on the meaning attached to traumatic experiences}

Firstly, personal trauma or trauma experienced by a close colleague seems to create traumatic memories, challenge the police officer's sense of invulnerability and trigger survival responses in the form of seeking similar situations to 'practise' more effective reactions in order to deal with the event, integrate the experience or try to change the outcomes.

Secondly, trauma involving the death of a colleague is accepted more easily if it occurred in the line of duty, which provides a more legitimate reason and meaning for the death. Such deaths are often handled in a cognitive and spiritual way but coping is devoid of emotional experiences, which cannot be allowed into the conscious mind because they may trigger defences of avoidance and learned helplessness.

Thirdly, stress reactions of anger, aggression and irritability after trauma may lead to a process whereby control is lost, which may trigger vulnerability. When this appears as a result of anger directed at perpetrators and criminals it can lead to frustration and temporary immobilisation but when it results from conflict with and judgements by colleagues it may lead to giving up and withdrawal.

Fourthly, the lack of support from colleagues and especially management after a traumatic event seems to create a sense of abandonment and helplessness and results in blaming and aggression towards the organisation. This may lead to a noncaring, non-supportive culture over a period of time.

\section{Working hypotheses on the systems psychodynamics operating in the South African Police Service environment}

Fifthly, the perceived level of competence amongst the members of a police unit seems to affect the identity of the unit in that it can either facilitate trust, relationships and 
relatedness or alternatively the perception amongst members that some members lack competence can cause mistrust and split the unit into two camps, namely the competent versus the non-competent, which will lead to vulnerability or the feeling that colleagues are unwilling to protect one.

The sixth hypothesis relates to the police culture, which essentially creates powerful parental figures in the form of leaders. These powerful leaders play a significant role in managing the organisational boundaries and anxieties of police officers by being role models of the values of the system as well as providing the recognition (symbolic and financial), which represents approval, acknowledgement, nurturance and safety.

The final three hypotheses relate to the transformational processes and dynamics in the system. When transformation involves rectifying the representivity of different racial groups in an organisation, the anxiety involved in 'replacing' members of one group with members of another group leads to projections of incompetence as a defence and a fear for own safety when one is dependent on a new member for one's safety. In spite of the need to feel safe, anxiety and resistance to change prevent the older members from mentoring the new members in fear of losing the team's identity and their own place in it.

The anxiety and fear experienced by a less experienced leadership during transformational processes leads to the withdrawal of delegated authority and a centralisation of power, resulting in unclear lines of command, confusion and mistrust. Poorly communicated role and task changes during periods of transformation in police cultures may be seen as de-authorising and punitive actions by the new leadership for past transgressions or non-performance whilst newly allocated roles and tasks are experienced as confusing, illogical and designed to test the competence of subordinates.

\section{Conclusion}

The study found a dissonance to exist between the dominant discourse on trauma in the SAPS and the individual experiences of police officers. Notwithstanding the fact that the participants acknowledge these incidents as severely traumatic, not one of the participants feels that they cannot cope with them. This contradicts the dominant discourse of the organisation, which mainly focuses its interventions on trauma-related instances. The focus of the Employee Assistance Services on trauma in the SAPS might serve to strengthen the dominant discourse of the organisation and may act as a facade that allows the organisation to demonstrate that they are doing something about trauma. This focus is politically more acceptable than admitting to the racial tension, injustices and insecurities generated by processes within the organisation.

Police officers are indeed exposed to multiple horrendously traumatic incidents which are often experienced as frightening and anxiety-provoking situations that render one powerless.
Feelings of being overwhelmed, powerless and helpless may have a significant impact on officers' self-esteem and damage their feelings of omnipotence and invulnerability, which are necessary to cope in the street environment. South African police officers often feel undervalued and unappreciated and experience their work as mainly insignificant and meaningless. It seems as if the organisation of the SAPS, functioning as a large group, often generates emotions which are unmanageable and uncontrollable. This is an anxietyprovoking experience for the individual and may certainly exacerbate the anxiety which results from exposure to trauma.

It is therefore safe to say that the effect of trauma exposure is aggravated by various contributing systems psychodynamics. The transformation process in the SAPS creates a tremendous amount of uncertainty and insecurity, which together with the absence of a supportive in-group identity, leave police officers feeling extremely vulnerable, exposed and out of control. This creates yet further anxiety. The changing discourse in the SAPS leads to intense feelings of disempowerment within the rank-and-file of the SAPS. Social immobilisation and paralysis restrict the potential of the organisation functioning as a large group (in psychoanalytic terms) to assist in integration. This in turn (ironically) inhibits growth and transformation.

The lack of a supportive structure in the organisation of the SAPS results in free-floating rather than contained anxiety. This has serious implications for the mental health of the organisation as well as its members. May et al. (1958, p. 17) state that when a culture is caught in the profound convulsions of a transitional period, the individuals in the society understandably suffer spiritual and emotional upheaval; and finding that the accepted mores and ways of thought no longer yield security, they tend either to sink into dogmatism and conformism, giving up awareness, or are forced to strive for a heightened self-consciousness by which to become aware of their existence with new conviction and on new bases. It seems as if the transformation process in the organisation of the SAPS has led chiefly to dogmatism. According to the data, racism, discrimination and prejudice still flourish; it is only the face of the target that has changed. It seems as if the attempt to redress old wrongs brings with it many new injustices.

The present study has distinct limitations. The study was conducted from the position of the specific cultural background of the researchers. That was a given situation and was acknowledged as such. This study's area of focus was complex, and the interpretation was far from exhaustive. Recommendations for future research are that this research may provide an impetus to further exploration and that it may contribute to a cognisance of the often complex and intricate consequences that flow from decisions, processes and changes. Furthermore, the need expressed by police officers to be heard carries the implied wish that, once their stories have been heard, things will change. 


\section{Acknowledgements Competing interests}

The authors declare that they have no financial or personal relationship(s) which may have inappropriately influenced them in writing this paper.

\section{Authors' contributions}

M.Y. (Clinical Psychologist) was the project leader, and P.K. (University of Johannesburg) and R.O. (University of South Africa) wrote and edited the manuscript academically.

\section{References}

Ainsworth, P.B. (1995). Psychology and policing in a changing World. Chichester: Wiley.

Anonymous. (2000, 8 November). Trauma in die polisie kan geweld kweek. Beeld. Retrieved n.d., from http://www.beeld.com

Botha, C.J. (2002). The anthropological-existential world of the present-day SA police person. Servamus, 95(3), 47-52.

Bion, W.R. (1961). Experiences in groups and other papers. New York: Basic Books. http://dx.doi.org/10.4324/9780203359075

Brewer, J.D. (1994). Black and blue policing in South Africa. Oxford: Clarendon Press.

Bruinsma, G.J.N., \& Zwanenburg, M.A. (Eds.). (1992). Methodology for management specialists: Trends and methods. Muiderberg: Coutinho.

Bucaille, L. (2006). Police officers and soldiers of apartheid: Losers in the new South Africa. International Social Science Journal, 58(189), 433-46. http://dx.doi. org/10.1111/j.1468-2451.2007.00642.x

Burgess, A., \& Holmstrom, L. (1974). The rape trauma syndrome. American Journal of Psychiatry, 131, 981-986.

Cole, P., \& Putnam, F.W. (1992). Effects of incest on self and social functioning: A developmental psychopathology perspective. Journal of Consulting and Clinical Psychology, 60, 174-184. http://dx.doi.org/10.1037/0022-006X.60.2.174 Figley, C. (1978). Stress disorders among Vietnam veterans. New York: Brunner/ Mazel.

Garland, C. (Ed.). (1998). Understanding trauma: A psychoanalytical approach. London: Duckworth.

Green, B.L., Wilson, J.P., \& Lindy, J.P. (1985). Conceptualizing post-traumatic stress disorder: A psychosocial framework. In C.R. Figley (Ed.), Trauma and its wake: The study of post-traumatic stress disorder, (pp. 53-69). New York: Brunner/Mazel.

Herman, J.L. (1992). Trauma and Recovery. New York: Basic Books.

Hoffman, L. (1993). A reflexive stance for family therapy. In S. McNamee \& K.J. Gergen (Eds.), Therapy as social construction, (pp.69-85). London: Sage.

Horowitz, M.J. (1986). Stress response syndromes. (2nd edn.). Northvale, NJ: Aronson.

Horowitz, M.J., \& Kaltreider, N.B. (1980). Brief psychotherapy of stress response syndromes. In T. Karasu \& L. Bellak (Eds.). Specialized techniques in individual psychotherapy, (pp. 162-183). New York: Brunner/Mazel.

Jacobs, E.W. (2000). Exploring women's talk of their experiences with anorexia nervosa. Unpublished master's dissertation, University of the Western Cape, Cape Town, South Africa.

Janoff-Bulman, R. (1985). The aftermath of victimization: Rebuilding shattered assumptions. In C.R. Figley (Ed.), Trauma and its wake: The study and treatment of post traumatic stress disorder, (pp. 15-35). New York: Brunner/Mazel.

Kassen, M., \& DiLalla, D. (2008). Maladaptive defense style and traumatic stress reactions in a specialized unit of the South African Police Service. Journal of Forensic Psychology Practice, 8(3), 262-279. http://dx.doi.org/10.1080/15228930802282014

Ketel (2008). Management capacity-building in the South African Police Service at station level. International Journal of Police Science and Management, 10(2), 145-164

Koortzen, P., \& Cilliers, F. (2002). The psychoanalytic approach to team development In R. Lowman (Ed.), The California School of Organizational Studies: Handbook of Organizational Consulting Psychology, (pp 220-235). Newark: Wiley.

Krystal, H. (1978). Trauma and affects. Psychoanalytic Child Study, 33, 81-116.

Lawrence, W.G., Bain, A., \& Gould, L. (1996). The fifth basic assumption. Free Associations, 6 (Part 1, No 37), 28-55.

Lindemann, E. (1944). Symptomatology and management of acute grief. American Journal of Psychiatry, 101, 141-148.

Lindy, J.D., \& Titchener, J. (1983). 'Acts of God and man': Long term character change in survivors of disasters and the law. Behavioral Science and the Law 1, 85-96. http://dx.doi.org/10.1002/bsl.2370010309
Mampane, N. (2010). Statement issued by Norman Mampane. POPCRU National Spokesperson.

Marshall, C., \& Rossman, G. (1995). Designing qualitative research. Newbury Park, CA: Sage.

Marks (2008). Looking different, acting different: Struggles for equality within the South African Police Service. Public Administration, 86(3), 643-658.

May, R., Angel, E., \& Ellenberger, H.F. (Eds.). (1958). Existence A new dimension in Psychiatry and Psychology. New York: Basic Books.

McFarlane, A.C. (1992). Avoidance and intrusion in posttraumatic stress disorder Journal of Nervous and Mental Disease, 180, 258-262. http://dx.doi. org/10.1097/00005053-199207000-00006

McGrath. (1992). Job experience and perceived job stress among police, correctional and probation/parole officers. Criminal Justice and Behavior, 19(3), 260-286. http://dx.doi.org/10.1177/0093854892019003004

Mostert, K., \& Rothmann, S. (2006). Work-related well-being in the South African Police Service. Journal of Criminal Justice, 34(5), 479-491. http://dx.doi. org/10.1016/j.jcrimjus.2006.09.003

Mouton, J. (1996). Understanding social research. Pretoria: Van Schaik.

Nel, J.A. (1994). A contextual approach to post-shooting trauma in the South African Police Service. Unpublished master's dissertation, University of South Africa, Pretoria.

Nel, J.A., \& Steyn, M. (1997). Safety and Security and Mental Health. In D. Foster (Ed.) Mental Health in South Africa. Cape Town: Lexicon.

Neumann, J.E. (1999). Systems psychodynamics in the service of political organizational change. In R. French \& R. Vince (Eds.), Group relations, management, and organization, (pp. 54-69). Oxford, UK: Oxford University Press.

Otto, H. (2002, November 25). When the price is too high. Pretoria News, p. 1 \& 4.

Pearlman, L.A., \& Saakvitne, K.W. (1995). Trauma and the therapist. New York: Norton.

Penn, P., \& Frankfurt, M. (1994). Creating a participant text: Writing, multiple voices, narrative multiplicity. Family Process, 33(3). http://dx.doi.org/10.1111/j.15455300.1994.00217.x

Pienaar, J., Rothmann, S., \& Van der Vijver, F.J.R. (2007). Occupational stress, personality traits, coping strategies, and suicide ideation in the South African Police Service. Criminal Justice and Behavior, 34, 246-258. http://dx.doi. org/10.1177/0093854806288708

Pynoos, R.S., \& Eth, S. (1985). Developmental perspectives on psychic trauma in childhood. In C.R. Figley (Ed.), Trauma and its wake. New York: Brunner/Mazel.

Reiker, P.P., \& Carmen, E.H. (1986). The victim-to-patient process: The disconfirmation and transformation of abuse. American Journal of Orthopsychiatry, 56, 360-370. $\mathrm{http}: / / \mathrm{dx}$.doi.org/10.1111/j.1939-0025.1986.tb03469.x

Republic of South Africa. (1998). Employment Equity Act, No. 55 of 1998. Pretoria: Government Printer.

Sapa. (2009, 30 September). Polisie kort berading. Retrieved n.d., from http:// afrikaans.news24.com

Schwartz, L.S. (1990). A biopsychosocial treatment approach to post-traumatic stress disorder. Journal of Traumatic Stress, 3, 221-238. http://dx.doi.org/10.1002/ jts.2490030205

Seedat, M., Van Niekerk, A., Jewkes, R., Suffla, S., \& Ratele, K. (2009). Violence and injuries in South Africa: Prioritising an agenda for prevention. Lancet, 374, 68-79. http://dx.doi.org/10.1016/S0140-6736(09)60948-X

South African Police Service. (1994). Change Management in the SAPS. (2nd draft). Unpublished report.

South African Police Service. (1995). SAPS RDP business plan. (3rd draft). Unpublished report.

Steinberg, J. (Ed). (2001). Crime wave: The South African underworld and its foes. Witwatersrand University Press.

Steyn (2007). 'Venus versus mars': An attitudinal comparison made at the start of South African police service basic training. International Journal of Police Science and Management, 9(2), 145-163.

Thom, A. (1995, August 8). Fivaz upset by police suicides. The Star, p. 3.

Uwe, F. (1998). An introduction to qualitative research. London: Sage.

Van der Kolk, B.A., McFarlane, A.C., \& Weisaeth, L. (Eds.). (1996). Traumatic stress: The effects of overwhelming experience on mind, body and society. New York: Guilford.

Van der Walt, M.J. (2001). 'n Groepanalitiese eksplorasie van psigiese uitbranding by sielkundiges in die Suid-Afrikaanse Polisiediens. Unpublished doctoral dissertation, University of Pretoria, Pretoria, South Africa.

Van der Westhuizen, H. (2001). The Evaluation of a Diversity Training Programme in the South African Police Service. Unpublished master's dissertation, Rhodes University, Grahamstown, South Africa.

Wisdom, C.S. (1989). The cycle of violence. Science, 24(4), 117-264.

White Paper on Reconstruction and Development. (1994). Government Gazette.

Yorke, C. (1986). Reflections on the problems of psychic trauma. The Psychoanalytic Study of the Child, 41, 221-236.

Young, A. (1995). The harmony of illusions: Inventing Post-Traumatic Stress Disorder. Princeton, NJ: Princeton University Press. 